\title{
Shape-controlled Synthesis of Dandelion-like Poly(m-phenylenediamine)
}

\author{
Tingting Guo ${ }^{1}$, Fang Liao ${ }^{1}$, Zhoufeng Wang ${ }^{1} \&$ Siwei Yang ${ }^{1}$ \\ ${ }^{1}$ Chemical Synthesis and Pollution Control Key Laboratory of Sichuan Province, School of Chemisty and \\ Chemical Industry, West Normal University, Nanchong, China \\ Correspondence: Fang Liao, Chemical Synthesis and Pollution Control Key Laboratory of Sichuan Province, \\ School of Chemisty and Chemical Industry, China West Normal University, Nanchong 637002, China. E-mail: \\ liaozhang2003@163.com
}

Received: February 22, 2012

Accepted: March 6, $2012 \quad$ Online Published: June 2, 2012

doi:10.5539/jmsr.v1n3p25

URL: http://dx.doi.org/10.5539/jmsr.v1n3p25

\begin{abstract}
A facile method was demonstrated to grow poly(m-phenylenediamine) (PmPD) microtube arrays and hierarchical dandelion-like microstructures, which was carried out by mixing ammonium persulfate (APS) aqueous and m-phenylenediamine solution in the presence of $\mathrm{Fe}\left(\mathrm{NO}_{3}\right)_{3}$ at room temperature. As-prepared PmPD microtubes were characterized by scanning electron microscopy (SEM), energy dispersive spectrometry (EDS), X-ray diffraction (XRD) and Fourier transform infrared spectroscopy techniques (FTIR). The influence of both temperature and concentration of $\mathrm{Fe}\left(\mathrm{NO}_{3}\right)_{3}$ on the morphology of PmPD was also investigated and they are found to play an important role in the formation of microtubes. Moreover, the growth process was tentatively proposed on the basis of different polymerization stages.
\end{abstract}

Keywords: poly(m-phenylenediamine), microtubes, hierarchical microstructures

\section{Introduction}

During the past years, Polyaniline (PANI) is one of the most studied conducting polymers (CPs) due to its chemical stability and relatively high conductivity. In addition to PANI, polymers based on aniline derivatives, such as phenylenediamine, have also received increasing attention mainly due to their apparently different characteristics compared with those widely researched CPs. For example, poly(o-phenylenediamine) (PoPD) and poly(p-phenylenediamine) (PpPD) microparticles show a unique ability to process heavy metal ions such as lead ions during water purification, because the ligands of these polymers can interact strongly with the metal ions and bind them. The PoPD have been used as catalysts, sensors and for the creation of electrochromic, which extends the applications of the conducting polymers. In addition, PmPD and PpPD have also been investigated in copolymerization with PANI. Moreover, various morphologies of poly(phenylenediamine), such as microrods, leaf-like microparticles, and nanobelts, have been prepared. Nevertheless, among the poly(phenylenediamine), PmPD have been the least studied, because of its weak reducing.

In this letter, an economic, simple route to prepare pure microtubes of PmPD on a large scale is demonstrated, which gave rise to dandelion-like architectures of PMPD hexagonal microtubes as a novel hierarchical structure. In this synthesis, the product of $\mathrm{Fe}\left(\mathrm{NO}_{3}\right)_{3}$ and $\mathrm{mPD}$ acts as a template for PmPD based on APS and mPD (scheme 1). Moreover, both the size and the morphology of the microstructures can be heavily influenced by the amount of ferric nitrate as well as the temperature. The detailed shape evolution process of PmPD microstructures is also discussed in this communication.

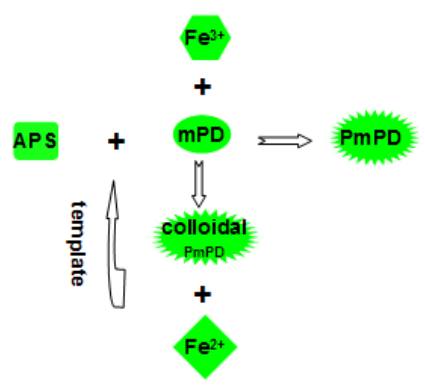

Scheme 1. Schematic reactions of formation of PmPD 


\section{Experimental}

\subsection{Materials}

Ferric nitrate $\left(\mathrm{Fe}\left(\mathrm{NO}_{3}\right)_{3}\right)$, m-phenylenediamine $(\mathrm{mPD})$ and ammonium persulfate (APS) were purchased from KeLong(Chengdu, China), All reagents were of analytical grade and used without further purification.

\subsection{Methods}

Typical synthetic processes of PmPD microtubes were as follows: $3 \mathrm{ml}$ of $\mathrm{Fe}\left(\mathrm{NO}_{3}\right)_{3}(20 \mathrm{mM})$ was added to $2 \mathrm{ml}$ of $\mathrm{mPD}(20 \mathrm{mM})$ with stirring, the reaction was allowed to proceed without agitation for $8 \mathrm{~min}$, and a light-red colloidal solution was abtained. Followed by adding $8 \mathrm{ml}$ of APS $(20 \mathrm{mM})$ to the above mixture and leaving the resulting solution at $20^{\circ} \mathrm{C}$ for $12 \mathrm{~h}$, a large quantity of brown precipitate occurred gradually. Finally, the product was washed with deionized water and acetone respectively until the filtrate became colorless and dried under vacuum at $40^{\circ} \mathrm{C}$ for $24 \mathrm{~h}$ (sample 1 ).

\subsection{Sample Characterizations}

The morphologies, chemical compositions and structure of the products were characterized using a combination of the following techniques: scanning electron microscope (SEM, JEOL JSM-6510LV) coupled with an energy-dispersive X-ray spectroscopy (EDS, Oxford instruments X-Max), X-ray diffraction (XRD, Rigaku Ultima IV, CuKa radiation) and Fourier transform infrared spectroscopy (FTIR, Thermo Scientific Nicolet 6700 FT-IR Spectrometer).

\subsection{Results and Discussions}

Figure 1a shows the morphology of the PmPD (sample 1). It is similar to the dandelion in shape, which consists of a large quantity of well-aligned hexagonal microtubes with a diameter about $0.5 \mu \mathrm{m}$. It should also be noted that there aren't irregular particles, and the dandelion-shaped superstructures undoubtedly become a well marked morphology of the product.

The chemical composition of sample 1 was determined by EDS (Figure 1b). The peaks of $\mathrm{C}$ and $\mathrm{N}$ were observed, indicating the product are formed from PmPD. The peaks of $\mathrm{O}$ and $\mathrm{S}$ can be attributed to the fact that the polymerization of MPD by APS yields positively charged PmPD structures and thus SO42- as counter ions diffuse into the PmPD for charge compensation. Sample 1 was also characterized by XRD in Figure 1c, the polymer exhibit a broad diffraction peak between $23^{\circ}$ and $27^{\circ}$. This is the typical characteristics for less ordered crystalline structure. The molecular structure of sample 1 was characterized by FTIR, as shown in Figure $1 \mathrm{~d}$. The adsorption peaks at 3431 and $3208 \mathrm{~cm}^{-1}$ correspond to the $\mathrm{N}-\mathrm{H}$ stretching mode. The peaks at 1628 and 1513 $\mathrm{cm}^{-1}$ are assigned to $\mathrm{C}=\mathrm{N}$ and $\mathrm{C}=\mathrm{C}$ stretching vibrations in phenazine structure, respectively. The peaks at 1398 and $1274 \mathrm{~cm}^{-1}$ are associated with the $\mathrm{C}-\mathrm{N}$ stretching in the benzenoid and quinoid imine units, respectively. The bands at 1124 and $1038 \mathrm{~cm}^{-1}$ are ascribed to the aromatic $\mathrm{C}-\mathrm{H}$ in plane bending mode. All the above observations indicate the successful formation of dandelion-like PmPD.
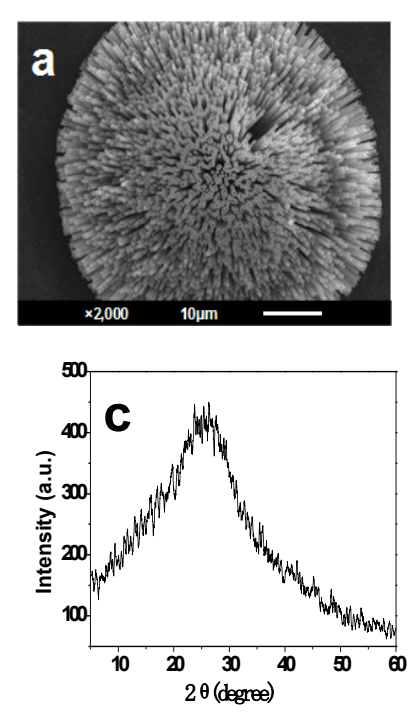
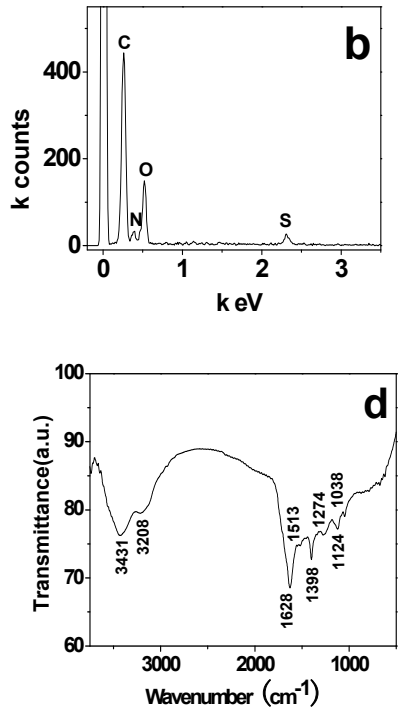

Figure 1. (a) SEM image, (b) Energy-dispersed spectrum, (c) XRD pattern and (d) FT-IR spectra of sample 1 
The concentration of $\mathrm{Fe}\left(\mathrm{NO}_{3}\right)_{3}$ is discovered to be vital to the formation and the assembly of the hexagonal microtubes, and its effect on the morphology of the product is exhibited in Figure 2. Figure 2a shows the SEM image of PmPd prepared without $\mathrm{Fe}\left(\mathrm{NO}_{3}\right)_{3}$, it is obvious that these particles are sphericals with a diameter about $900 \mathrm{~nm}$. Interestingly, the hexagonal microtubes was synthesized under condition of $3 \mathrm{ml} \mathrm{Fe}\left(\mathrm{NO}_{3}\right)_{3}$ (sample 1), as shown in Figure $2 \mathrm{~b}$. However, as the volume of $\mathrm{Fe}\left(\mathrm{NO}_{3}\right)_{3}$ increases to $7 \mathrm{ml}$, it is surprising to find the microdisks with a section size about $1 \mu \mathrm{m}$ (Figure 2c).
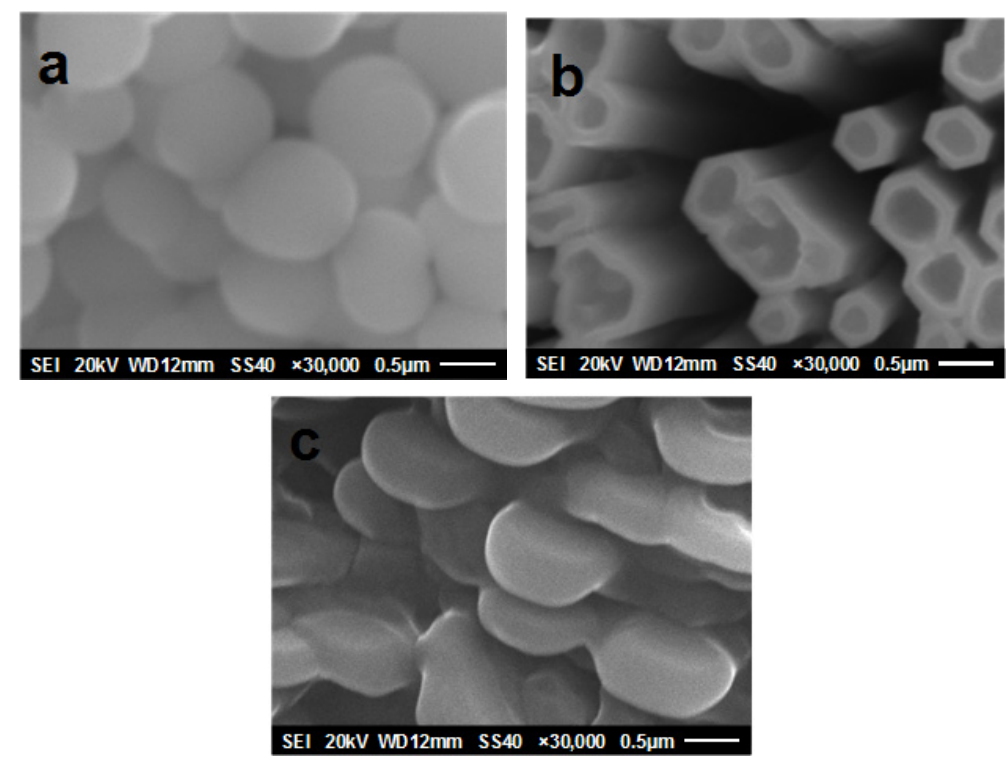

Figure 2. SEM images of PmPD synthesized with different volumes of $\mathrm{Fe}\left(\mathrm{NO}_{3}\right)_{3}(20 \mathrm{mM})$ solution: (a)0 ml (b) $3 \mathrm{ml}(\mathrm{c}) 7 \mathrm{ml}$

Moreover, the temperature also makes a great difference to the morphology, as shown in Figure 3. Figure 3a shows the SEM image of PmPd prepared at $0{ }^{\circ} \mathrm{C}$. It is found as-formed structures are hexagonal microdisks with a diameter about $2.5 \mu \mathrm{m}$. Figure $3 \mathrm{~b}$ shows the SEM image of microtubes based dandelion-like PmPd prepared at $20{ }^{\circ} \mathrm{C}$ (sample 1). Figure $3 \mathrm{~b}$ shows the SEM image of PmPD prepared at $70{ }^{\circ} \mathrm{C}$. It is clear to see that cylindrical microrods appear in the product, but they stick together. Thus, it is manifested that $20{ }^{\circ} \mathrm{C}$ is the optimal temperature in the preparation processes of microtubes based dandelion-like PmPD.
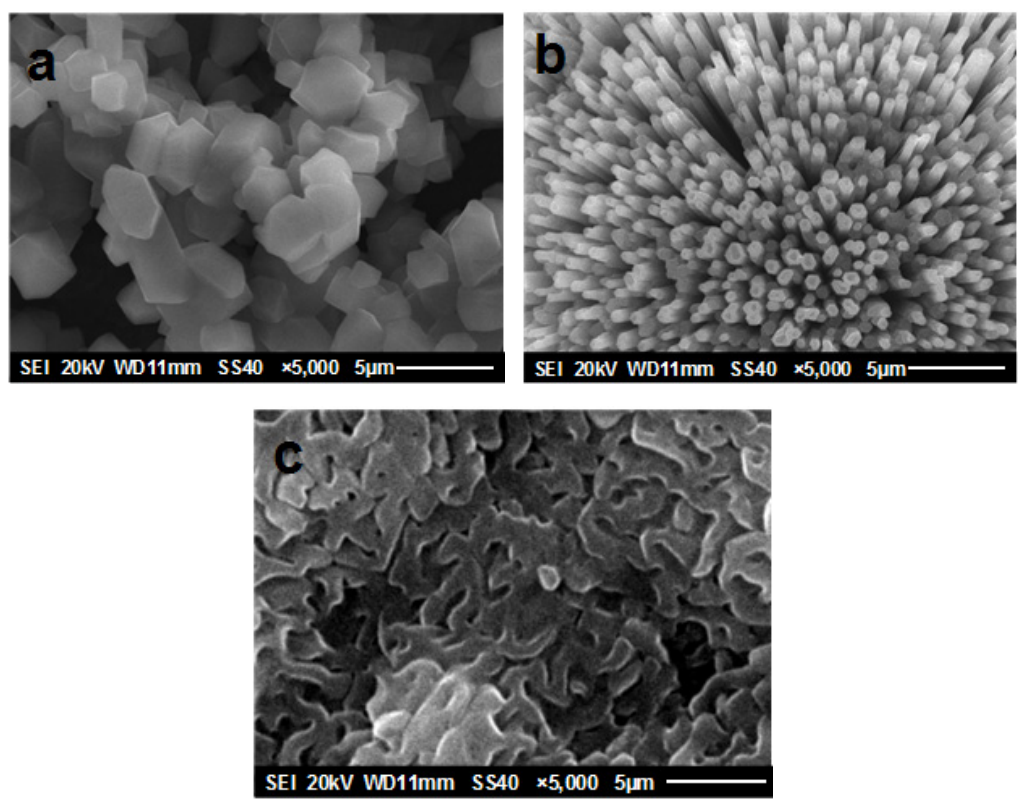

Figure 3. SEM images of PmPD synthesized at different temperature: (a) $0{ }^{\circ} \mathrm{C}$ (b) $20{ }^{\circ} \mathrm{C}$ (c) $70{ }^{\circ} \mathrm{C}$ 
To gain insight into the growth of the hexagonal microtubes and their assembly into dandelion-like superstructures (sample 1), we collected the products at different polymerization stages for SEM investigation, as displayed in Figure 4. Figure 5 shows a schematic diagram to farther illustrate the formation process of PmPD microstructures. At the early stage of polymerization (5h), the tadpole-like nucluei are formed (Figure $4 \mathrm{a}$ ), and they acted as crystal seeds to direct the vertical growth of PmPD microtubes. When the reaction is continued to 9h, the half-full microrods are yielded as the different vertical growth of PmPD (Figure $4 \mathrm{~b}_{2}$ ). And the primal dandelion-like structures would also grow as shown in Figure 5, in accordance with the result of electronic microscopic observation in Figure $4 b_{1}$. Subsequently, after a reaction period of $12 \mathrm{~h}$, the half-full microrods evolve into hexagonal microtubes, accompanied with assembly into the ultima dandelion-like superstructures (Figure 4c), which may be attributed superior vertical growth of PmPD on the walls of microrods as shown in the second route of Figure 5. However, the detailed formation mechanism is not clear and further investigation was required.
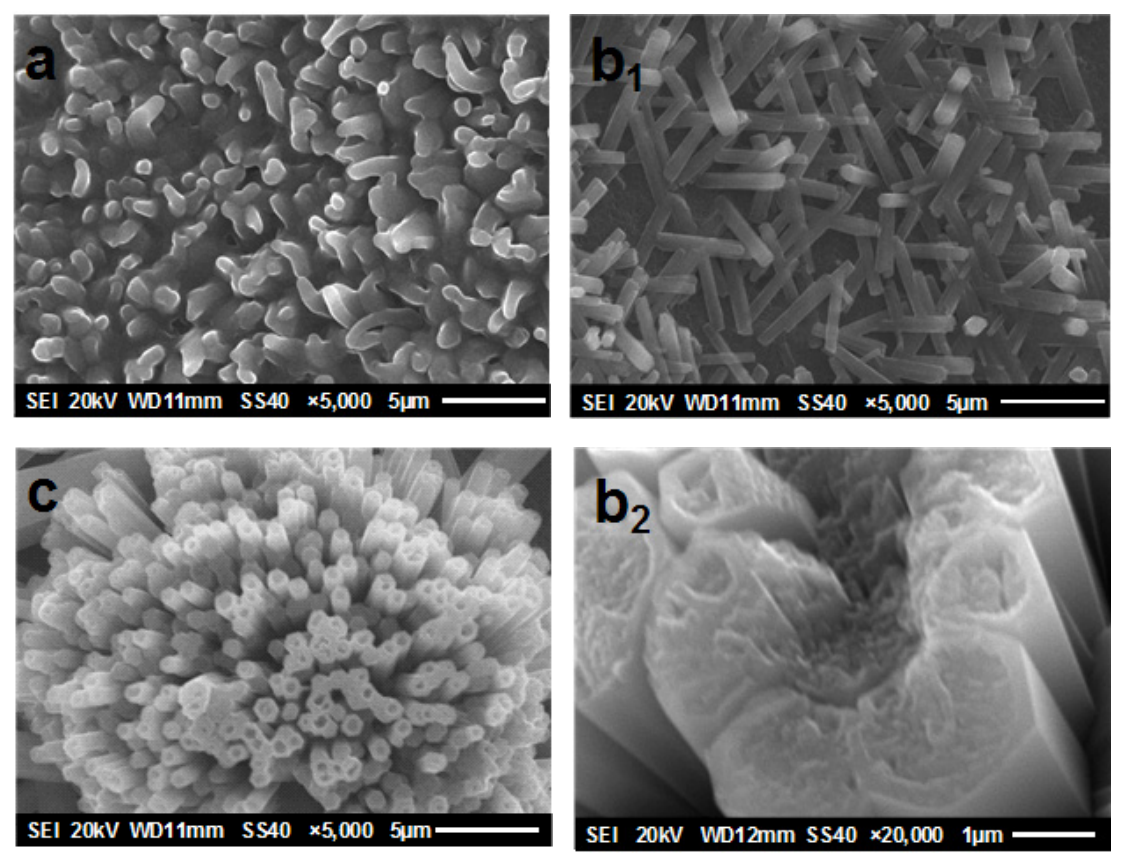

Figure 4. SEM images of PmPD synthesized at different time: $(a) 5 \mathrm{~h}\left(\mathrm{~b}_{1}\right),\left(\mathrm{b}_{2}\right) 9 \mathrm{~h}(\mathrm{c}) 12 \mathrm{~h}$, the volumes of $\mathrm{Fe}\left(\mathrm{NO}_{3}\right)_{3}(20 \mathrm{mM})$ solution is $3 \mathrm{ml}$, and the temperature is $20^{\circ} \mathrm{C}$

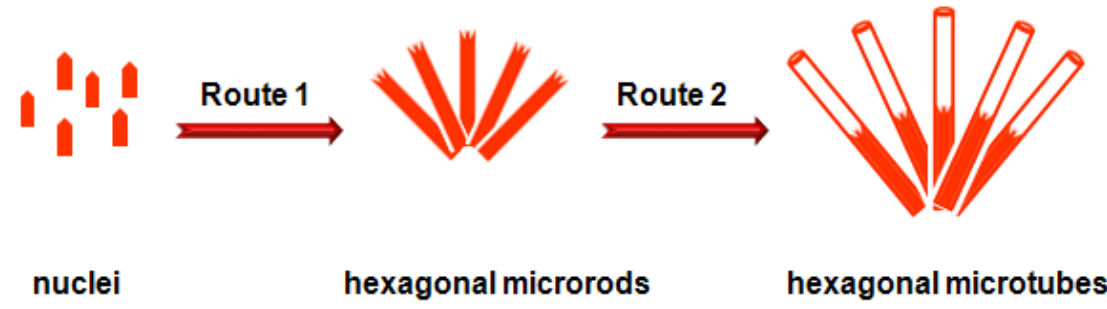

Figure 5. Schematic illustration of the formation process of PmPD microstructures

\section{Conclusion}

A facile approach has been described to fabricate PmPD dandelion-like hierarchical architectures of hexagonal microtubes for the first time. The morphology of the product could be influenced by time, temperature and concentration of $\mathrm{Fe}\left(\mathrm{NO}_{3}\right)_{3}$. It provides us an economic route to obtain pure microtubes of PmPD. And the proposed route might be applied to synthesize other polymer superstructures based on 1D nanostructures. More importantly, microtubes based dandelion-like PmPd might find potential applications in catalysts, biosensors, the creation of electrochromic and the removal of toxic heavy metal ions in contaminated water. 


\section{References}

Curtis, C. L. (1994). Conducting polymer connections for molecular devices. Adv. Mater., 6(9), 688-692. http://dx.doi.org/10.1002/adma.19940060917

Dai, H., Wu, Q., Sun, S., \& Shiu, K. J. (1998). Electrochemical quartz crystal microbalance studies on the electropolymerization processes of ortho-phenylenediamine in sulfuric acid solutions. Electroanal Chem., 456(1-2), 47-59. http://dx.doi.org/10.1016/S0022-0728(98)00211-3

Han, J., Song, G., \& Guo, R. (2007). Nanostructure-based leaf-like polyaniline in the presence of an amphiphilic triblock copolymer. Adv. Mater., 19(19), 2993-2999. http://dx.doi.org/10.1002/adma.200602635

Hao, Q., Sun, B., Yang, X., Lu, L., Wang, X. (2009). Synthesis and characterization of poly (o-phenylenediamine) hollow multi-angular microrods by interfacial method. Mater Lett., 63(2), 334-336. http://dx.doi.org/10.1016/j.matlet.2008.10.041

He, D., Wu, Y., \& Xu, B. Q. (2007). Formation of 2,3-diaminophenazines and their self-assembly into nanobelts in aqueous medium. European Polymer Journal, 43(9), 3703-3709. http://dx.doi.org/10.1016/j.eurpolymj.2007.06.038

Li, G., \& Zhang, Z. (2004). Synthesis of dendritic polyaniline nanofibers in s surfactant gel. Macromolecules, 37(8), 2683-2685. http://dx.doi.org/10.1021/ma035891k

Li, G., Pang, S., Xie, G., Wang, Z., Peng, H., \& Zhang, Z. (2006). Synthesis of radially aligned polyaniline dendrites. Polymer., 47(8), 1456-1459. http://dx.doi.org/10.1016/j.polymer.2005.12.062

Li, X. G., Huang, M. R., Duan, W., \& Yang, Y. L. (2002). Novel multifunctional polymers from aromatic diamines by oxidative polymerizations. Chem. Rev.,102(9), 2925-3030. http://dx.doi.org/10.1021/cr010423z

Li, X. G., Lu, Q. F., \& Huang, M. R. (2006). Rapid and Effective Adsorption of Lead Ions on Fine Poly(phenylenediamine) Microparticles. Chem., 12(16), 4341-4350.

Lu, X. F., Mao, H., \& Zhang, W. J. (2007). Preparation and characterization of poly (o -phenylenediamine) microrods using ferric chloride as an oxidant. Materials Letters., 61(6), 1400-1403. http://dx.doi.org/10.1016/j.matlet.2006.07.040

Malitesta, C., Palmisano, F., Torsi, L., \& Zambonin, P. G. (1990). Glucose fast-response amperometric sensor based on glucose oxidase immobilized in an electropolymerized poly(o-phenylenediamine) film. Anal. Chem., 62(24), 2735-2740. http://dx.doi.org/10.1021/ac00223a016

Malitesta, C., Palmisano, F., Torsi, L., \& Zambonin, P. G. (1990). Glucose fast-response amperometric sensor based on glucose oxidase immobilized in an electropolymerized poly(ortophenylenediamine) film. Anal. Chem., 62(24), 2735-2740. http://dx.doi.org/10.1021/ac00223a016

Mallick, K., Witcomb, M. J., Dinsmore, A., \& Scurrell, M. S. (2005). Fabrication of a metal nanoparticles and polymer nanofibres composite material by an in situ chemical synthetic route. Langmuir, 21(17), 7964-7967. http://dx.doi.org/10.1021/la050534j

Ogura, K., Shiigi, H., Nakayama, M., \& Fujii, A. J. (1998) Thermogravimetric/Mass and Infrared Spectroscopic Properties and Humidity Sensitivity of Polyaniline Derivatives/Polyvinyl Alcohol Composites. Electrochem. Soc., 145(10), 3351-3357. http://dx.doi.org/10.1149/1.1838811

Park, M. C., Sun, Q., \& Deng, Y. (2007). Polyaniline microspheres consisting of highly crystallized nanorods. Macromol. Rapid Commun., 28(11), 1237-1242. http://dx.doi.org/10.1002/marc.200700066

Pei, Q., Yu, G., Zhang, C., Yang, Y., \& Heeger, A. G. (1995). Polymer Light-Emitting Electrochemical Cells. Science, 269(5227), 1086-1088. http://dx.doi.org/10.1126/science.269.5227.1086

Prokes, J., Krivka, I., Kuzel, R., Stejskal, J., Kratochvil, P., \& Int. J. (1996). Electrlcal properties of $\begin{array}{llll}\text { poly(aniline-co-p-phenylenediamine) } & \text { copolymers. } & \text { Electron., } & 81(4),\end{array}$ http://dx.doi.org/10.1080/002072196136580

Sulimenko, T., Stejskal, J., \& Prokes, J. J. (2001). Poly(phenylenediamine) dispersions. Colloid Interface Sci., 236(2), 328-334. http://dx.doi.org/10.1006/jcis.2000.7415

Sun, X. P., \& Hagner, Matthias. (2007). Mixing Aqueous Ferric Chloride and O-Phenylenediamine Solutions at Room Temperature: A Fast, Economical Route to Ultralong Microfibrils of Assemblied O-Phenylenediamine Dimers. Langmuir., 23(21), 10441-10444. http://dx.doi.org/10.1021/la701378y

Sun, X., Dong, S., \& Wang, E. (2004). One-Step Preparation and Characterization of Poly(propyleneimine) 
Dendrimer-Protected Silver Nanoclusters. Macromolecules, $\quad 37(19), \quad$ 7105-7108. http://dx.doi.org/10.1021/ma048847t

Wang, J. J., Jiang, J., Hu, B., \& Yu, S. H. (2008). Uniformly-Shaped Poly (p-phenylenediamine) (PpPD) Microparticles: Shape Control Synthesis and Their Potential Application in Removal of Lead Irons in Water. Adv. Funct. Mater., 18(7), 1105-1111. http://dx.doi.org/10.1002/adfm.200700583

Zhang, L. Y., Chai, L. Y., \& Wang, H. Y. (2010). Facile synthesis of one-dimensional self-assembly oligo(o-phenylenediamine) materials by ammonium persulfate in acidic solution. Materials Letters, 64(10), 1193-1196. http://dx.doi.org/10.1016/j.matlet.2010.02.048

Zhang, Y. W., Wang, L., Tian, J. Q., \& Sun, X. P. (2011). Ag@Poly(m-phenylenediamine) Core-Shell Nanoparticles for Highly Selective, Multiplex Nucleic Acid Detection. Langmuir, 27(6), $2170-2175$. http://dx.doi.org/10.1021/la105092f

Zhou, C. Q., Han, J., \& Guo, R. (2009). Polyaniline fan-like architectures of rectangular sub-microtubes synthesized in dilute inorganic Acid solution. Macromol. Rapid Commun., 30(3), 182-187. http://dx.doi.org/10.1002/marc.200800585

Zhou, C., Han, J., Song, G., \& Guo, R. (2008). Fabrication of polyaniline with hierarchical structures in alkaline solution. European Polymer Journal, 44(9), 2850-2858. http://dx.doi.org/10.1016/j.eurpolymj.2008.01.025

Zhu, Y., Hu, D., Wan, M. X., Jiang, L., \& Wei, Y. (2007). Conducting and Superhydrophobic Rambutan-like Hollow Spheres of Polyaniline. Adv. Mater., 19(16), 2092-2096. http://dx.doi.org/10.1002/adma.200602135 